\title{
Morphological and Physiological Pattern of the Liver in Patients with Metabolic Syndrome
}

\author{
Khalil A.K, Seham A Omar, Abdou M, Greesh M and Hamdy Sliem*
}

Department of Internal Medicine, Suez Canal University, Ismailia, Egypt

\begin{abstract}
The metabolic syndrome is a combination of metabolic and underlying risk factors that increase a person's risk for atherosclerotic cardiovascular disease and type 2 diabetes mellitus. In Egypt; there are no obvious previous researches had been conducted on the hepatic manifestations of metabolic syndrome. So our study was aimed to determine the impact of metabolic syndrome in the morphological and physiological pattern of the liver. One hundred sixty five patients with IDF criteria of metabolic syndrome: 91 (55.2\%) males and 74 (44.8\%) females were included. The range of ages was 21-68 years (mean $\pm S D=46.50 \pm 12.79$ ). All were subjected for studying the morphological and physiological changes of the liver. There was significant positive correlation between waist circumference, diastolic blood pressure, number of criteria and liver enzymes (ALT, AST). Also, significant positive correlations between systolic blood pressure, FBS and ALT, AST and triglycerides were recorded. On the other hand, there was significant inverse correlation between HDL-C and liver enzymes (ALT, AST). The Best fitting multiple logistic regression models for predictors of Abnormal liver Echo pattern was waist circumference and triglycerides. In conclusion, metabolic syndrome has critical impact not only on the cardiovascular system, but also has an adverse effect on the morphology and physiology of the liver.
\end{abstract}

Keywords: Metabolic syndrome; Hepatic morphology and physiology

\section{Introduction}

The metabolic syndrome is a combination of metabolic and underlying risk factors that increase a person's risk for atherosclerotic cardiovascular disease (CVD) and type 2 diabetes mellitus [1]. The prevalence of the metabolic syndrome in the United States was evaluated using both the International Diabetes Federation criteria (IDF) and National Cholesterol Education Program -Adult Treatment Panel 3 (NCEP ATP III) diagnostic criteria in 3601 men and women aged 20 years and older who participated in the National Health and Nutrition Education Survey (NHANES) in 1999 to 2002. Using NCEP ATP III criteria, the total unadjusted prevalence of the metabolic syndrome was $34.5 \%$ (IDF, 39.0\%); 33.7\% among men (IDF, 39.9\%) and $35.4 \%$ among women (IDF, 38.1\%) [2,3].

Nonalcoholic fatty liver disease (NAFLD) is an increasing recognized clinical pathologic condition that may progress to end stage liver disease. The pathological picture resembles that of alcoholinduced liver injury, but occurs in nonalcoholic patients. Nonalcoholic fatty liver disease refers to wide spectrum of liver damage ranging from simple steatosis, steato-hepatitis, advanced fibrosis up to cirrhosis [4].

Steatosis is referred to the accumulation of droplet of triglycerides in hepatocytes with normal cells [5]. While Nonalcoholic steatohepatitis (NASH) is a form of chronic hepatitis with histological features of alcohol induced liver disease that occurs in persons who do not consume a significant amount of alcohol ( $<20 \mathrm{~g} /$ day $)$. NASH has gained more clinical importance recently because it was suggested to be a major cause of unexplained raised transaminases [6]. Steatosis alone is associated with good prognosis, whereas NASH can progress to fibrosis and cirrhosis in up to $30 \%$ of cases, potentially leading to liver failure and hepatocellular carcinoma [7].

NAFLD affects $22 \%$ of the general population in different countries. NASH could present in one third of NAFLD. Age activity of steatohepatitis and established fibrosis predispose to cirrhosis, which has a 7 to 10 years related mortality of $12 \%$ to $25 \%$. Many cases of cryptogenic cirrhosis are likely end stage NASH. While end stage NAFLD currently account for $4 \%$ to $10 \%$ of liver transplant $[8,9]$.

There is no specific cause for fatty liver. The pathogenesis of NAFLD is believed to involve in two steps. The first step involves insulin resistance and obesity and cause development of steatosis. The second step is oxidative stress, activating an inflammatory response and causing NASH [10-12]. In Egypt; there are no obvious previous researches had been conducted on the hepatic manifestations of metabolic syndrome. So our study was conducted to determine the impact of metabolic syndrome on the morphological and physiological pattern changes of the liver.

\section{Patients and Methods}

This study was cross-sectional descriptive study to determine hepatic morphological and physiological changes in patients with metabolic syndrome.The study was carried out in the Outpatient Clinic of the Internal Medicine Department of Suez Canal University Hospital.

\section{Inclusion criteria were}

1- Patients above age of twenty

2- All patients presented with criteria of metabolic syndrome according to international diabetes federation (IDF) as follows [14]:

${ }^{*}$ Corresponding author: Hamdy Sliem, Professor, Suez canal university, Interna medicine, Ismailia, 41522, Egypt, Tel: +20107612359; E-mail: hamdy.sliem@ yahoo.com

Received October 27, 2011; Accepted December 14, 2011; Published December 20, 2011

Citation: Khalil AK, Omar SA, Abdou M, Greesh M, Sliem H (2011) Morphological and Physiological Pattern of the Liver in Patients with Metabolic Syndrome. Diabetes Metab S2:004. doi:10.4172/2155-6156.S2-004

Copyright: ( $) 2011$ Khalil AK, et al. This is an open-access article distributed unde the terms of the Creative Commons Attribution License, which permits unrestricted use, distribution, and reproduction in any medium, provided the original author and source are credited. 
Citation: Khalil AK, Omar SA, Abdou M, Greesh M, Sliem H (2011) Morphological and Physiological Pattern of the Liver in Patients with Metabolic Syndrome. J Diabetes Metab S2:004. doi:10.4172/2155-6156.S2-004

Page 2 of 4

A-Central obesity (defined as waist circumference with ethnicity specific values) in Egypt and Arab:

- Male $\geq 94 \mathrm{~cm}$ and Female $\geq 80 \mathrm{~cm}$.

B-Plus any two of the following four factors:

- Raised triglycerides $\geq 150 \mathrm{mg} / \mathrm{dL}(1.7 \mathrm{mmol} / \mathrm{L})$.

- Reduced HDL cholesterol:

$<40 \mathrm{mg} / \mathrm{dL}(1.03 \mathrm{mmol} / \mathrm{L})$ in males.

$<50 \mathrm{mg} / \mathrm{dL}(1.29 \mathrm{mmol} / \mathrm{L})$ in females.

- Blood pressure: Systolic BP $\geq 130$ or diastolic BP $\geq 85 \mathrm{~mm} \mathrm{Hg}$.

- Fasting plasma glucose:

(FPG) $\geq 100 \mathrm{mg} / \mathrm{dL}$ ( $5.6 \mathrm{mmol} / \mathrm{L}$ ), or previously diagnosed type 2 diabetes.

3- Patients with negative viral markers (HBsAg, HCV-Abs).

\section{Exclusion criteria were}

1. Person consuming alcohol or drug abusers for any duration.

2. Patients with positive viral markers (HBsAg, HCV-Abs).

3. Clinical possibility of other types of liver disease in the patients, (Confirmed by appropriate investigations).

4. Patients with drug history (antibiotics, analgesics, etc...)

5. Pregnancy or breast feeding.

\section{Data collection was through}

Full medical history taking, complete medical examination, waist circumference by measuring tab, blood pressure by stethoscope and sphygmomanometer, laboratory investigations as liver functions tests, viral markers (HBsAg, HCV-Ab), Lipid profile (Triglycerides, HDL, and LDL), fasting plasma glucose level and abdominal ultrasound.

\section{Results}

This study included 165 patients with IDF criteria of metabolic syndrome: $91(55.2 \%)$ were males and $74(44.8 \%)$ were females. The range of ages was $21-68$ years (mean $\pm \mathrm{SD}=46.50 \pm 12.79) .93(56.4 \%)$ patients were from urban areas, $72(43.6 \%)$ were from rural areas. The study showed $91(100 \%)$ males with waist circumference $\geq 94 \mathrm{~cm}, 74$ (100\%) females with waist circumference $\geq 80 \mathrm{~cm}$. The most common presented components were triglycerides 138 (83.6\%) patients as seen in table 1 (Table 1 ).

On the studied patients, the mean ALT level was $59.52 \pm 53.03$; $106(64.2 \%)$ patients had elevated ALT level. AST mean level $54.98 \pm$ 26.72, $106(64.2 \%)$ patients had elevated AST level. Serum bilirubin mean $0.96 \pm 0.18$ and only $6(3.6 \%)$ patient had elevated level. Alkaline phosphatase mean $123.74 \pm 29.49,54$ (32.7\%) patients had elevated level. prothrombine time mean $14.03 \pm 1.08,20(15.2 \%)$ patients had prolonged prothrombine time. While serum albumin mean $4.03 \pm$ 0.39, 6 (3.6\%) patients were hypoalbuminic (Table 2).

According to results in this study, $134(81.2 \%)$ patients had abnormal liver size (132 enlarged, 2 shrunken), 149 (90.3\%) patients had abnormal liver echo-pattern (147 bright liver, 2 coarse liver). Two (1.2\%) patients had irregular liver border, dilated portal vein and attenuated hepatic veins. Regarding gall bladder features: 101 (61.2\%) patients had thickened wall, 94 (57\%) with mud, 92 (55.8\%) had gall bladder stones, 76 (46.1\%) with cholesterol deposits, 106 (64.2\%) with contracted gallbladder.

Also our study showed that there is significant relation between gender and liver enzymes as most elevated liver enzymes (ALT, AST) were in males $66(40 \%)$ patients. No significant relation between liver size, echopattern and gender. There was significant relation between

\begin{tabular}{|c|c|c|c|c|}
\hline Total No. (\%) & Frequency & Gender & $\begin{array}{l}\text { According to IDF } \\
\text { criteria }\end{array}$ & Component of IDF \\
\hline \multirow{2}{*}{$165(100 \%)$} & 91 & Male & $\geq 94 \mathrm{~cm}$ & \multirow{2}{*}{$\begin{array}{l}\text { Waist } \\
\text { circumference }\end{array}$} \\
\hline & 74 & Female & $\geq 80 \mathrm{~cm}$ & \\
\hline \multirow{2}{*}{$101(61.3 \%)$} & 58 & Male & \multirow{2}{*}{$\geq 130 \mathrm{~mm} \mathrm{Hg}$} & \multirow{4}{*}{ Systolic BP } \\
\hline & 43 & Female & & \\
\hline \multirow{2}{*}{$64(38.7 \%)$} & 33 & Male & \multirow{2}{*}{$<130 \mathrm{~mm} \mathrm{Hg}$} & \\
\hline & 31 & Female & & \\
\hline \multirow{2}{*}{97 (58.8\%) } & 48 & Male & \multirow{2}{*}{$\geq 85 \mathrm{~mm} \mathrm{Hg}$} & \multirow{4}{*}{ Diastolic BP } \\
\hline & 49 & Female & & \\
\hline \multirow{2}{*}{$68(41.2 \%)$} & 43 & Male & \multirow{2}{*}{$<85 \mathrm{~mm} \mathrm{Hg}$} & \\
\hline & 25 & Female & & \\
\hline \multirow{2}{*}{$138(83.6 \%)$} & 68 & Male & \multirow{2}{*}{$\geq 150 \mathrm{mg} / \mathrm{dL}$} & \multirow{4}{*}{ Triglycerides } \\
\hline & 70 & Female & & \\
\hline \multirow{2}{*}{$27(16.4 \%)$} & 23 & Male & \multirow{2}{*}{$<150 \mathrm{mg} / \mathrm{dL}$} & \\
\hline & 4 & Female & & \\
\hline \multirow{2}{*}{$112(67.8 \%)$} & 57 & Male & $<40 \mathrm{mg} / \mathrm{dL}$ & \multirow{4}{*}{ HDL-C } \\
\hline & 55 & Female & $<50 \mathrm{mg} / \mathrm{dL}$ & \\
\hline \multirow{2}{*}{$53(32.2 \%)$} & 34 & Male & \multirow{2}{*}{$<50 \mathrm{mg} / \mathrm{dL}$} & \\
\hline & 19 & Female & & \\
\hline \multirow{2}{*}{$121(73.4 \%)$} & 73 & Male & \multirow{2}{*}{$\geq 100 \mathrm{mg} / \mathrm{dL}$} & \multirow{4}{*}{$\begin{array}{l}\text { Fasting blood } \\
\text { glucose }\end{array}$} \\
\hline & 48 & Female & & \\
\hline \multirow{2}{*}{$44(26.6 \%)$} & 18 & Male & \multirow{2}{*}{$<100 \mathrm{mg} / \mathrm{dL}$} & \\
\hline & 26 & Female & & \\
\hline
\end{tabular}

Table 1: Presented IDF components of metabolic syndrome.

\begin{tabular}{|l|l|l|l|l|}
\hline $\begin{array}{l}\text { Total } \\
\text { No. }(\%)\end{array}$ & $\begin{array}{l}\text { Laboratory } \\
\text { findings }\end{array}$ & Mean \pm SD & Laboratory tests & $\begin{array}{l}\text { Laboratory } \\
\text { tests }\end{array}$ \\
\hline $59(35.8 \%)$ & Normal & $59.52 \pm 53.03$ & ALT & ALT \\
\hline $106(64.2 \%)$ & Elevated & $54.98 \pm 26.72$ & AST & AST \\
\hline $59(35.8 \%)$ & Normal & $0.96 \pm 0.18$ & S.bilirubin & S.bilirubin \\
\hline $106(64.2 \%)$ & Elevated & $123.74 \pm 29.49$ & ALK & ALK \\
\hline $159(96.4 \%)$ & Normal & $14.03 \pm 1.08$ & PT & PT \\
\hline $6(3.6 \%)$ & Elevated & $4.03 \pm 0.39$ & S.ALB & S.ALB \\
\hline $111(67.3 \%)$ & Normal & $123.74 \pm 29.49$ & Normal & $111(67.3 \%)$ \\
\hline $54(32.7 \%)$ & Elevated & Elevated & $54(32.7 \%)$ \\
\hline $140(84.8 \%)$ & Normal & \multirow{2}{*}{$14.03 \pm 1.08$} & Normal & $140(84.8 \%)$ \\
\hline $20(15.2 \%)$ & Elevated & Elevated & $20(15.2 \%)$ \\
\hline $159(96.4 \%)$ & Normal & \multirow{2}{*}{$4.03 \pm 0.39$} & Normal & $159(96.4 \%)$ \\
\hline $6(3.6 \%)$ & Decreased & & Decreased & $6(3.6 \%)$ \\
\hline
\end{tabular}

Table 2: Physiological pattern of the liver.

liver ecchopattern and AST/ALT ratio as most of abnormal liver echopattern patients are of AST/ALT ratio >1 (56.4\%), and also there is significant relation between liver size and AST/ALT ratio as most of abnormal liver size patients are of AST/ALT ratio $>1$ (61.2\%), (Table 3).

There was significant positive correlation between waist circumference, diastolic blood pressure, number of criteria and liver enzymes (ALT, AST). Also, there was significant positive correlation between systolic blood pressure, FBS and ALT, significant positive correlation between triglycerides and AST. On the other hand there was significant inverse correlation between HDL-C and liver enzymes (ALT, AST). The Best fitting multiple logistic regression models for predictors of abnormal liver Echo-pattern was waist circumference and triglycerides (Table 4 ).

\section{Discussion}

This study was cross-sectional descriptive study to determine hepatic morphological and physiological changes in patients with 


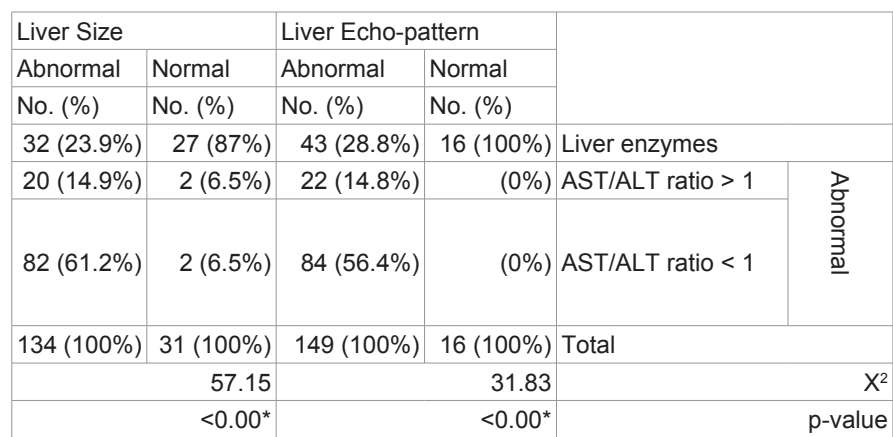

Table 3: morphological pattern of the liver.

\begin{tabular}{|c|c|c|c|c|c|c|}
\hline \multicolumn{2}{|c|}{$\begin{array}{l}95.0 \% \text { C.I. for } \\
\text { Odds ratio }\end{array}$} & \multirow{2}{*}{ Odds Ratio } & \multirow{2}{*}{$p$-value } & \multirow{2}{*}{\begin{tabular}{|l} 
Standard Error \\
5.05 \\
\end{tabular}} & \multirow{2}{*}{\begin{tabular}{|l|} 
Beta \\
-14.13
\end{tabular}} & \multirow[b]{2}{*}{ Constant } \\
\hline Upper & Lower & & & & & \\
\hline 1.2 & 1.03 & 1.12 & $0.03^{*}$ & 0.04 & 5.05 & $\begin{array}{l}\text { Waist } \\
\text { Circumference }\end{array}$ \\
\hline 1.05 & 1.01 & 1.03 & $0.00^{*}$ & 0.01 & 0.03 & Triglycerides \\
\hline
\end{tabular}

Table 4: Multiple logistic regression models for predictors of abnormal liver Echopattern

metabolic syndrome. One hundred sixty five patients with age over 20 years presented with criteria of metabolic syndrome according to international diabetes federation (IDF) were studied.

\section{Socio-demographic characteristics}

The majority were males (55.2\%). This higher incidence of the disease in men than in women in our study sample may be due to role of estrogen [13]. Ninety three (56.4\%) lives in urban areas while $72(43.6 \%)$ were living in rural areas, indicating a relatively high socioeconomic status among them which predispose them to have a high incidence of physical inactivity and unhealthy dietary habits as mentioned by other studies $[14,15]$.

\section{Characteristics of metabolic syndrome}

In our study we used the IDF diagnostic criteria for diagnosis of metabolic syndrome. We found that waist circumference mean 108.84 \pm 8.94. All males (55.2) had waist circumference $\geq 94 \mathrm{~cm}$, while all females (44.8) had waist circumference $\geq 80 \mathrm{~cm}$. Another study by Bethene [16] revealed that abdominal obesity concerned was about $53 \%$ of risk factors of metabolic syndrome. Jawad [17] stated that the age-adjusted prevalence of abdominal obesity was markedly higher among women than men. This may be due to the increase prevalence of metabolic syndrome in females with increase age as estrogen levels decrease in the blood.

The most common presented component was triglycerides as 138 (83.6\%) patients with triglycerides level $\geq 150 \mathrm{mg} / \mathrm{dL}$. Another study by Bethene [16] revealed that, hypertriglyceridemia was about $31 \%$. Jawad [17] stated that approximately $20 \%$ of the population had hypertriglyceridemia. The study revealed that, the most second common prevalent component was the FBS as $73.4 \%$ patients with FBS level $\geq 100 \mathrm{mg} / \mathrm{Dl}$, while in the study by Bethene [16] showed that prevalence of hyperglycemia was $39 \%$ and was the most frequently occurring risk factors for metabolic syndrome. Also, Jawad [17] stated that approximately $20 \%$ of the population had high FBS.

Recorded low HDL levels in current study was also reported by Abdul-Rahim et al. [18] among Palestinians of the West Bank. According to National Institutes of Health [19], the low HDL cholesterol levels may have several causes, such as elevated triglycerides, overweight and obesity, diabetes, and physical inactivity, many of which are associated with insulin resistance. On the other hand, Huda Al-Ghareeb [20] stated that, the criteria with the highest prevalence was low HDL-c while the lowest was the impaired fasting blood sugar. Raised plasma TG was found in $24.8 \%$, increased waist circumference was found in $52.4 \%$, and high BP was found in $39.4 \%$.

In other studies, Giulio et al. [21] stated that the prevalence of positive criteria for the metabolic syndrome was exceedingly variable in the whole population, ranging from $11 \%$ (hyperglycemia, men) to 77\% (hypertension, women). A low HDL-cholesterol level was present in $30 \%$ to $42 \%$ of cases and the arterial pressure criteria were fulfilled in $34 \%$ to $83 \%$ of cases. Waist circumference exceeded the threshold for abdominal obesity in the large majority of obese patients. Peter [15] showed that $69.6 \%$ patients had elevated serum triglyceride. There were $35.5 \%$ patients whose HDL cholesterol was below the normal range. Hypertension was presented in $66.1 \%$ patients while diabetes mellitus was noted in $47.7 \%$ of the patients included in this series.

\section{Liver functions}

According to liver functions we found that the mean ALT level was $59.52 \pm 53.03 ; 64.2 \%$ patients had elevated ALT level. AST mean level $54.98 \pm 26.72$ with $64.2 \%$ patients had elevated AST level.

Serum bilirubin mean $0.96 \pm 0.18$ and only $3.6 \%$ patient with elevated level. Alkaline phosphatase mean $123.74 \pm 29.49$ with $32.7 \%$ had elevated level. Prothrombine time mean $14.03 \pm 1.08$ with $15.2 \%$ patients had prolonged prothrombine time. While serum albumin mean $4.03 \pm 0.39$ with $3.6 \%$ patients were hypoalbuminic.A study presented by Peter [15] showed that the mean SGPT level was $68.7 \pm$ 56.0 while that of the SGOT was $34.9 \pm 15.3$. Elevated SGPT was noted in $65.7 \%$ of the patients while elevated SGOT was noted in $33.3 \%$.

\section{Ultrasonographic features}

According to liver features: 134 (81.2\%) patients had abnormal liver size (132 enlarged, 2 shrunken), 149 (90.3\%) patients had abnormal liver echo-pattern (147 bright liver, 2 coarse liver), and males were dominant than females about the criteria of liver abnormalities. 1.2\% patients had irregular liver border, dilated portal vein and attenuated hepatic veins. A study presented by Peter [15] showed that nonalcoholic fatty liver disease diagnosed by ultrasonography was noted in $51 \%$ of patients with metabolic syndrome. As reported by Park et al [22] NAFLD was found in $35.2 \%$ of the patients in his study. Most of the steatotic patients presented echogenicity compatible with mild fatty accumulation, followed in frequency by the moderate and severe phenotypes. No gender adjustments were made, because reports have usually described similar frequencies among men and women aged 55 years and over.

Masahide et al [11] reported that NAFLD more prevalent in males than females. Neuschwander-Tetri et al [12] stated that they found a higher incidence of the NAFLD in men than in women in their study sample. Another study by Peter [15] stated that prevalence of NAFLD among patients with metabolic syndrome were $64.2 \%$ in males and $35.7 \%$ in females. Regarding to gall bladder features: $61.2 \%$ patients had thickened wall, $57 \%$ with mud, $55.8 \%$ had gallbladder stones, $46.1 \%$ with cholesterol deposits, $64.2 \%$ with contracted gallbladder. Common bile duct and spleen features were normal in all patients.

\section{Some important relations}

Also in this study we found that the number of diagnostic components of IDF criteria among male and female was as following; 
three components are equal in distribution among both males and females $(16.4 \%)$, four components were more in males $(24.2 \%)$, while five components were more in females (17.6\%). Mean number of criteria among female patients $(4.03 \pm 0.88)$ was higher than mean in males $(3.97 \pm 0.75)$ but there is no significant relation.

Another study by Jawad [17] stated that all other components of metabolic syndrome were more common in men than women. The presence of multiple metabolic disorders is associated with a potentially progressive, severe liver disease. The increasing prevalence of obesity, coupled with diabetes, dyslipidemia, hypertension, and ultimately the metabolic syndrome puts a very large population at risk of forthcoming liver failure in the next decades [21]. 36\% of patients had normal range liver enzymes while 51\% patients had AST/ALT ratio less than 1 and $13 \%$ patients with ratio more than 1 . Another study by Salem [14] stated that Elevated liver enzymes levels are considered a consequence of liver damage due to fatty acid infiltration and inflammatory stimuli, and recent findings indicate that serum levels of these enzymes are associated with multiple components of the metabolic syndrome. Increases in ALT are positively associated with each component.

The current study revealed significant relation between gender and liver enzymes as most elevated liver enzymes (ALT, AST) were in males (66) $40 \%$ patients. Also this study showed that the relation between address and liver size was highly significant as most of abnormal liver size (enlarged, shrunken) are lives in urban area which may be due to relatively high socioeconomic status among them which predispose them to have a high incidence of physical inactivity and unhealthy dietary habits. Also our results showed significant relation between liver echopattern and AST/ALT ratio as most of abnormal liver ecchopattern patients are of AST/ALT ratio >1 (56.4\%). In comparison to Yung-Hsuan et al [23] whom stated that bright liver and elevated ALT level were independently related to the risk of having the metabolic syndrome. In addition, the present study showed that there was significant relation between liver size and AST/ALT ratio as most of abnormal liver size patients are of AST/ALT ratio>1 (61.2\%). In previous study, Jeanne [24] denoted that, AST/ALT ratio $>1$ may also indicate more severe disease.

Significant positive correlation between waist circumference, diastolic blood pressure, number of criteria and liver enzymes (ALT, AST) was detected. Furthermore, there was significant positive correlation between systolic blood pressure, FBS and ALT. In addition, significant positive correlation between triglycerides and AST was recorded. On the other hand, there was significant inverse correlation between HDL-C and liver enzymes (ALT, AST). A study by Oh et al [25] showed that, increases in ALT level are positively associated with each component of the metabolic syndrome. While Giulio et al [21] reported only aminotransferase levels were higher among individual criteria for the metabolic syndrome.

\section{Conclusion}

Metabolic syndrome has critical impact not only on the cardiovascular system, but also has an adverse effects on the morphology and physiology of the liver.

\section{References}

1. Grundy SM, Cleeman JI, Daniels SR, Donato KA, Eckel RH, et al. (2005) Diagnosis and management of the metabolic syndrome An American Heart Association/National Heart, Lung, and Blood Institute Scientific Statement. Circulation 112: 2735-2752.

This article was originally published in a special issue, Metabolic Syndrome: Diabetes handled by Editor(s). Dr. Eiji Oda, Tachikawa Medical Center, Japan
2. Ford ES (2005) Prevalence of the Metabolic Syndrome Defined by the International Diabetes Federation among Adults in the US. Diabetes Care 28 2745-2749.

3. Hu G, Qiao Q, Tuomilehto J, Eliasson M, Feskens EJ, et al. (2004) Plasma insulin and cardiovascular mortality in non-diabetic European men and women. A meta-analysis of data from eleven prospective studies. The DECODE Insulin Study Group. Diabetologia; 47: 1245-1256.

4. Angulo P (2002) Non-alcoholic fatty liver disease. N. Engl. J. Med; 346:12211231.

5. Daniel S, Ben-Menachem T, Vasudevan G, Ma CK, Blumenkehl M (1999) Prospective evaluation of unexplained chronic liver transaminase abnormalities in asymptomatic and symptomatic patients. Am J Gastroenterology 94: 3010 3014.

6. Sanyal AJ (2002) AGA technical review on Nonalcoholic fatty liver disease Gastroenterology 123: 1705-1725.

7. Ruhl CE, Everhart JE (2003) Determinants of the association of over weight with elevated serum alanine aminotransferase activity in the United States. Gastroenterology J 124: 71-79.

8. Farrell GC, George J, dela M et al. (2005) Fatty Liver Disease, NASH and Related Disorders. Malden MA: Blackwell Publishing: 1-319.

9. Day C, Saksena S (2002) Nonalcoholic steatohepatitis.Definitions and pathogenesis. J Gastroenterol Hepatol 17: S377-S384.

10. Medina J, Fernandez-Salazar LI, Garcia-Buey L, Moreno-Otero R (2004) Approach to the pathogenesis and treatment of nonalcoholic steatohepatitis. Diabetes Care 27: 2057-2066.

11. Masahide H, Takao K, Noriyuki T, Nakagawa T, Taniguchi H, et al. (2005) The Metabolic Syndrome as a Predictor of Nonalcoholic Fatty Liver Disease. Ann of Internal Medicine 143: 722-728.

12. Neuschwander-Tetri BA, Caldwell SH (2003) Nonalcoholic steatohepatitis: summary of an AASLD Single Topic Conference. Hepatology 37: 1202-1219.

13. Hewitt KN, Pratis K, Jones ME, Simpson ER (2004) Estrogen replacement reverses the hepatic steatosis phenotype in the male aromatase knockout mouse. Endocrinology 145: 1842-1848.

14. Morrison J (2004) Childhood obesity in the United States features and figures. The Journal of Clinical Endocrinology \& Metabolism 89: 2526-2539.

15. Peter LL, Tan J (2006) Prevalence of metabolic syndrome among patients with non-alchoholic liver disease. Phil J Gastroenterol 2: 14-18.

16. Ervin RB (2009) Prevalence of Metabolic Syndrome Among Adults 20 Years of Age and Over, by Sex, Age, Race and Ethnicity, and Body Mass Index Nat Health Stat Report 5: 1-7.

17. Al-Lawati JA, Mohammed AJ, Al-Hinai HQ, Jousilahti P (2003) Prevalence of the Metabolic Syndrome among Omani Adults. Diabetes Care 26: 1781-1785

18. Abdul-Rahim HF, Husseini A, Bjertness E, Giacaman R, Gordon NH, et al. (2001) The metabolic syndrome in the West Bank population: an urban-rural comparison. Diabetes Care 24: 275-279.

19. National Institutes of Health: Third Report of the National Cholesterol Education Program (NCEP) Expert Panel on Detection, Evaluation, and Treatment of High Blood Cholesterol in Adults (Adult Treatment Panel III). National Institutes of Health, 2001

20. Huda Al-Ghareeb (2007) Prevalence of metabolic syndrome among selected Kuwaiti patients. Middle East Journal of Family Medicine 5 (6).

21. Marchesini G, Bugianesi E, Forlani G, Cerrelli F, Lenzi M, et al. (2003) Nonalcoholic Fatty Liver, Steatohepatitis, and the Metabolic Syndrome. Hepatology 37: 917-923.

22. Park SH, Jeon WK, Kim SH, Kim HJ, Park DI, et al. (2006) Prevalence and risk factors of non-alcoholic fatty liver disease among Korean adults. $J$ Gastroenterol Hepatol 21: 138-143.

23. Shen YH, Yang WS, Lee TH, Lee LT, Chen CY, et al. (2005) Bright Liver and Alanine Aminotransferase Are Associated with Metabolic Syndrome in Adults. Obes Res 13: 1238-1245.

24. Clark JM (2006) The Epidemiology of Nonalcoholic Fatty Liver Disease in Adults. J Clin Gastroenterol 40: S5-S10.

25. Oh SY, Cho YK, Kang MS, Yoo TW, Park JH, et al. (2006) The association between increased alanine aminotransferase activity and metabolic factors in nonalcoholic fatty liver disease. Metabolism 55: 1604-1609. 